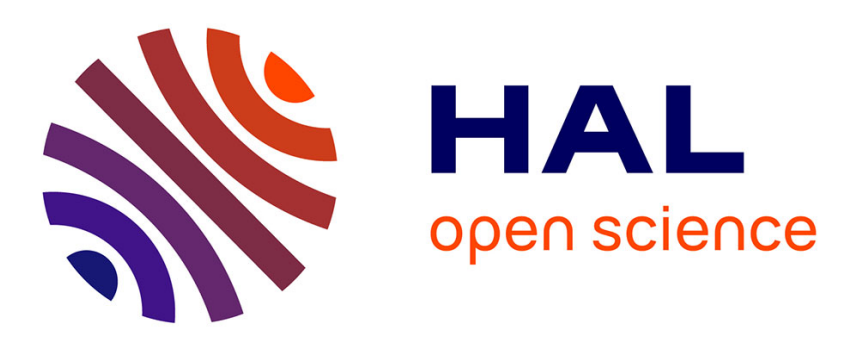

\title{
Effect of land-ice melting and associated changes in the AMOC result in little overall impact on oceanic CO 2 uptake
}

\author{
D. Swingedouw, L. Bopp, A. Matras, P. Braconnot
}

\section{- To cite this version:}

D. Swingedouw, L. Bopp, A. Matras, P. Braconnot. Effect of land-ice melting and associated changes in the AMOC result in little overall impact on oceanic CO 2 uptake. Geophysical Research Letters, 2007, 34 (23), pp.L23706. 10.1029/2007GL031990 . hal-03023504

\section{HAL Id: hal-03023504 https://hal.science/hal-03023504}

Submitted on 25 Nov 2020

HAL is a multi-disciplinary open access archive for the deposit and dissemination of scientific research documents, whether they are published or not. The documents may come from teaching and research institutions in France or abroad, or from public or private research centers.
L'archive ouverte pluridisciplinaire HAL, est destinée au dépôt et à la diffusion de documents scientifiques de niveau recherche, publiés ou non, émanant des établissements d'enseignement et de recherche français ou étrangers, des laboratoires publics ou privés. 


\title{
Effect of land-ice melting and associated changes in the AMOC result in little overall impact on oceanic $\mathrm{CO}_{2}$ uptake
}

\author{
D. Swingedouw, ${ }^{1}$ L. Bopp, ${ }^{1}$ A. Matras, ${ }^{1}$ and P. Braconnot ${ }^{1}$ \\ Received 11 September 2007; revised 26 October 2007; accepted 6 November 2007; published 6 December 2007.
}

[1] The impact of Greenland Ice Sheet (GIS) melting and associated weakening in the Atlantic Meridional Overturning Circulation (AMOC) on carbon uptake is quantitatively evaluated using coupled climate and biogeochemistry models. We compare two 140-yr global warming scenarios, forced by the same increase in atmospheric $\mathrm{CO}_{2}$, but with different GIS melting rates. The AMOC weakening in our 2 scenarios is $-47 \%$ and $-21 \%$ at $4 \times \mathrm{CO}_{2}$ when the melting of GIS is or is not considered, respectively. We find that GIS melting and AMOC-induced weakening have little influence on the $\mathrm{CO}_{2}$ uptake. By isolating the specific effects of salinity and temperature changes on carbon uptake, we find that opposing processes tend to limit the effect of GIS melting. Indeed, in the GIS melting scenario, less saline and cooler waters in high latitudes northern seas tend to increase $\mathrm{CO}_{2}$ uptake and counter-balance the decreasing $\mathrm{CO}_{2}$ uptake that follows from circulation changes alone. Citation: Swingedouw, D., L. Bopp, A. Matras, and P. Braconnot (2007), Effect of land-ice melting and associated changes in the AMOC result in little overall impact on oceanic $\mathrm{CO}_{2}$ uptake, Geophys. Res. Lett., 34, L23706, doi:10.1029/ 2007GL031990.

\section{Introduction}

[2] Anthropogenic $\mathrm{CO}_{2}$ emissions will result in substantial climate change in the coming century. Many feedbacks will respond to the $\mathrm{CO}_{2}$ perturbation and, if they are positive (negative), will tend to enhance (dampen) global warming. The most important feedbacks in the climate system are associated with water vapor and albedo [Hansen et al., 1984]. Another possible feedback, which has been recently identified [Klepper and de Haan, 1995] and confirmed in General Circulation Models [Cox et al., 2000; Friedlingstein et al., 2001], is related to the carbon cycle response to global warming. It has been shown that anthropogenic climate change could reduce both ocean and land carbon uptake, thereby further increasing atmospheric $\mathrm{CO}_{2}$ concentrations. The strength of this feedback can be estimated as the increased amount of carbon in the atmosphere due to the response of the carbon cycle to climate change. Despite the fact that, thus far, all models simulate a positive feedback, there is still a large uncertainty on the magnitude of this feedback, between $+20 \mathrm{ppm}$ and

\footnotetext{
${ }^{1}$ Laboratoire des Sciences du Climat et de l'Environnement, L'Institut Pierre-Simon Laplace, Gif-sur-Yvette, France.
}

Copyright 2007 by the American Geophysical Union. 0094-8276/07/2007GL031990
$+200 \mathrm{ppm}$ in 2100 according to the models participating in $\mathrm{C}^{4} \mathrm{MIP}$ [Friedlingstein et al., 2006]. This large uncertainty is due to the uncertain responses of the land and ocean carbon cycles.

[3] For the ocean, the integrated $\mathrm{CO}_{2}$ uptake reduction due to global warming (IPCC SRES emission scenario A2) from 1860 to 2100 varies from 64 to $222 \mathrm{PgC}$ for the models participating in $\mathrm{C}^{4} \mathrm{MIP}$ [Friedlingstein et al., 2006]. Several effects contribute to this reduction. $\mathrm{CO}_{2}$ uptake is directly affected by an increase in temperature via a decrease in solubility. Indirectly, an increase in surface temperature stratifies the surface ocean, which in turn decreases the Mixed Layer Depth (MLD), ocean mixing and the potential to take up anthropogenic carbon. The changes in the hydrological cycle also impact $\mathrm{CO}_{2}$ uptake through the influence of salinity on solubility and MLD. In addition, it has been argued that the weakening of the Atlantic Meridional Overturning Circulation (AMOC) in response to global warming could have a large impact on carbon uptake. Using a carbon model forced with ocean dynamics from a simulation wherein the AMOC had collapsed, Sarmiento and Le Quéré [1996] showed that ocean circulation changes explain $85 \%$ of the total reduction in $\mathrm{CO}_{2}$ uptake. However, in this experiment, temperature was fixed at the initial seasonally varying steady-state ocean values. This experimental design therefore only captures the dynamic impact of AMOC changes and not the associated impact on temperature. More recently, other studies have confirmed a reduction in the oceanic uptake of $\mathrm{CO}_{2}$ due to global warming conditions and quantified the effect of SST warming, reduced ocean circulation and marine biology changes on these reduction [Sarmiento et al., 1998; Matear and Hirst, 1999; Joos et al., 1999; Plattner et al., 2001]. None of these studies has evaluated the potential impact of Greenland Ice Sheet (GIS) melting and associated changes in AMOC on the $\mathrm{CO}_{2}$ uptake. Moreover the role of AMOC changes in terms of circulation changes and related modifications of temperature and salinity has been investigated in the context of present day and paleoclimate conditions [Marchal et al., 1998; Schmittner et al., 2007] but never for future climate change.

[4] In this study, we quantify the role of GIS melting and associated AMOC changes on the oceanic uptake of $\mathrm{CO}_{2}$ using a state-of-the-art coupled model. We analyze two transient experiments from Swingedouw et al. [2006] (hereinafter referred to as S2006) in which the atmospheric $\mathrm{CO}_{2}$ concentration is increased by $1 \% / \mathrm{yr}$ following the CMIP2 protocol [Meehl et al., 2000]. In a first experiment, the melting of GIS is taken into account, which results in a $47 \%$ decrease of the AMOC at $4 \times \mathrm{CO}_{2}$. In a second experiment, 
Table 1. Simulations Description and Cumulative $\mathrm{CO}_{2}$ Uptake After 140 Years in $\mathrm{PgC}$

\begin{tabular}{llc}
\hline Name & \multicolumn{1}{c}{ Description } & $\mathrm{CO}_{2}$ Uptake \\
\hline CTL & Control simulation & 638.4 \\
GW1 & Transient simulation with ice-sheet melting & 567.9 \\
GW2 & Transient simulation with no ice-sheet melting & 571.3 \\
Exp1 & Sensitivity experiment similar to GW2 but with & 580.7 \\
& $\quad$ GW1 temperature \\
Exp2 & Sensitivity experiment similar to GW2 but with & 587.3 \\
$\quad$ GW1 salinity \\
Exp3 & Sensitivity experiment similar to GW2 but with & 572.4 \\
& $\quad$ GW1 sea-ice cover \\
\hline
\end{tabular}

the GIS melting is not considered and the decrease of the AMOC is only $21 \%$ at $4 \times \mathrm{CO}_{2}$ (see S2006, for more details).

[5] In addition to changes in the ocean circulation, the two experiments differ substantially with respect to the changes in temperature, salinity and sea-ice cover that result. Land-ice melting causes a freshening of the North Atlantic. This effect is amplified by the weakening of the AMOC which imports less salinity to the North Atlantic. Sea surface temperature and sea-ice cover are also affected by the changes in the AMOC. Here, we will quantify the effect of all these GIS melting induced changes on $\mathrm{CO}_{2}$ uptake.

\section{Experimental Design}

[6] Climate-induced changes in the ocean are calculated with version 4 of the Institut Pierre Simon Laplace oceanatmosphere coupled model (IPSL-CM4 [Marti et al., 2005; Swingedouw et al., 2007]). We use the simulations of S2006 to investigate direct and indirect effects of land-ice melting and $\mathrm{AMOC}$ changes on oceanic $\mathrm{CO}_{2}$ uptake. Monthly mean output of the climate simulations is used to force an "offline" version of the global ocean carbon model PISCES [Aumont and Bopp, 2006]. PISCES uses the carbonate system formulation recommended by the Ocean CarbonCycle Model Intercomparison Project (OCMIP) and includes a simple marine ecosystem model, with 4 plankton functional groups (nanophytoplankton, diatoms, microzooplankton and mesoplankton). Nutrient co-limitation of phytoplankton growth is a function of N, P, Si and Fe. The iron cycle is explicitly modeled including input from atmospheric dust and coastal sediments. In the water column, sinking of particulate carbon is explicitly considered using a simple 2 size-classes model for the particulate organic carbon.

[7] PISCES has been forced by transient climatologies of 3 climate simulations from IPSL-CM4 (CTL, WIS and NIS simulations of S2006). 'CTL' is a control pre-industrial climate simulation and the two others are global warming scenarios forced by a $1 \% / \mathrm{yr}$ increase in atmospheric $\mathrm{CO}_{2}$ starting from pre-industrial conditions and in which GIS melting is taken into account (GW1) or not (GW2). The same atmospheric change in $\mathrm{CO}_{2}$ concentration $(+1 \% / \mathrm{yr})$ has been applied to the three biogeochemical simulations (CTL, GW1 and GW2, Table 1). The effects of global warming on the ocean carbon uptake, as well as the specific impact of land-ice melting are isolated using these 3 experiments. The reduction in AMOC is larger in GW1 than in
GW2. In the North Atlantic, salinity and temperature are lower in GW1 than in GW2 and sea ice cover is higher in GW1 than in GW2.

[8] The effect of GIS melting on the ocean $\mathrm{CO}_{2}$ uptake is isolated through the comparison of GW1 and GW2. We also consider complementary experiments to address the specific effects of land-ice melting and induced AMOC changes on ocean $\mathrm{CO}_{2}$ uptake. The effect of temperature changes alone (Exp1) is isolated by forcing PISCES with GW2 fields, but with oceanic temperature taken from GW1. We employ an identical strategy to isolate the effect of salinity (Exp2) and sea-ice cover (Exp3). Note that in these experiments we isolate the direct effects of GIS melting induced changes in temperature, salinity and ice-cover on the carbon cycle (solubility, chemistry and biology), but not through changes in ocean dynamics (Table 1). The effect of circulation has not been separated from biology, since export production is intimately related to the nutrient fields in our model and hence to circulation. The "circulation and biological" effect is computed by subtracting the specific effects of temperature, salinity and ice-cover (from Exp1 to 3) from the difference GW1-GW2. As non-linear effects can affect the response, this is only an approximation of this effect. Mixed layer effects are also included in this "circulation and biological" effect.

[9] A historical simulation was also conducted with PISCES in order to validate the present model against observations for anthropogenic $\mathrm{CO}_{2}$ uptake (HIS). It begins in 1860 and is forced until the year 1994 by observed atmospheric $\mathrm{pCO}_{2}$ concentrations [Etheridge et al., 1998; Keeling and Whorf, 2005] and the transient climatology of a historical run with the same coupled climate model.

\section{Results}

[10] The PISCES model succeeds in reproducing the main features of the observed anthropogenic carbon uptake. The total anthropogenic uptake amounts to $106 \mathrm{PgC}$ in the model for year 1994 and compares well with observationbased estimates of $118 \pm 19 \mathrm{PgC}$ [Sabine et al., 2004]. Figure 1 shows that the zonal mean anthropogenic carbon in the Atlantic basin for year 1994 of our HIS simulation is in good agreement with the estimate of Sabine et al. from observations and the use of the $\Delta \mathrm{C}^{*}$ method. The penetration of anthropogenic carbon is maximal at high latitudes, particularly in the North Atlantic where its penetration to $3000 \mathrm{~m}$ depth is well captured by HIS. In the South Atlantic, the penetration is maximal at $40^{\circ} \mathrm{S}$ and reaches $1500 \mathrm{~m}$ depth in the simulation, as well as in the observations. We note however, that the penetration of anthropogenic carbon in northern high latitudes is underestimated (Figure 1). This is certainly due to the underestimation of the AMOC in the model $(11 \mathrm{~Sv})$, which results in a weak ventilation of the Atlantic water mass.

[11] In the CTL simulation, ocean $\mathrm{CO}_{2}$ uptake increases to $5.8 \mathrm{PgC} / \mathrm{yr}$ at $4 \times \mathrm{CO}_{2}$ (Figure $2 \mathrm{c}$ ). When the climate change impact is included (in GW1 simulation), the ocean $\mathrm{CO}_{2}$ uptake at $4 \times \mathrm{CO}_{2}$ is reduced by $13.8 \%$ to $5.0 \mathrm{PgC} / \mathrm{yr}$. When integrated over 140 years, this reduction amounts to $70.5 \mathrm{PgC}$ (Figure 2d), corresponding to an additional $16 \mathrm{ppm}$ of $\mathrm{CO}_{2}$ in the atmosphere (assuming an airborne fraction of $50 \%$ ). 
a) Observations

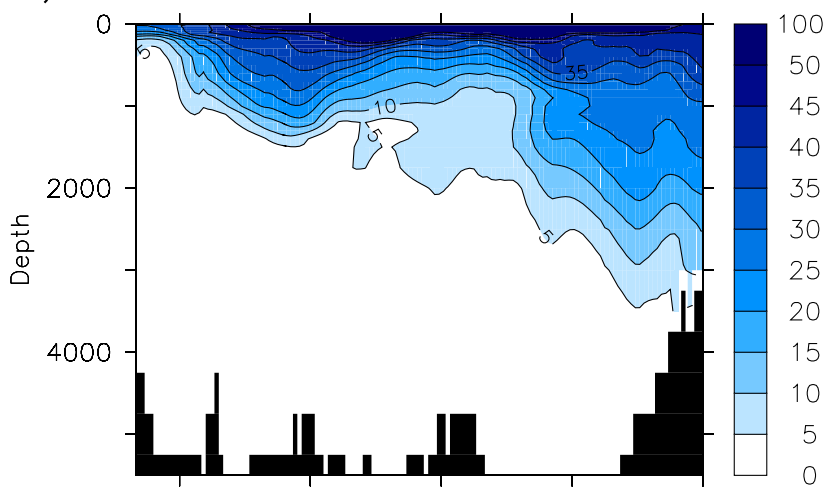

b) HIS

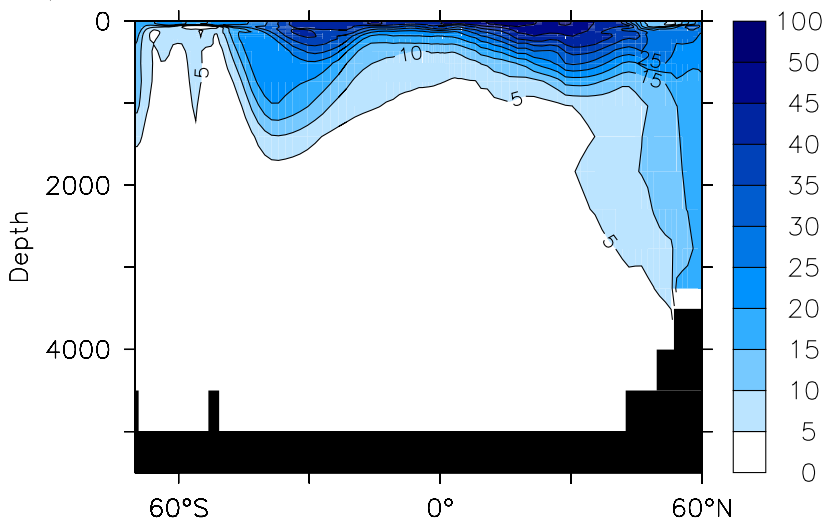

Figure 1. Zonal means of anthropogenic dissolved inorganic carbon (DIC) in the Atlantic basin (a) estimated from observations [Sabine et al., 2004], and (b) modeled in the HIS simulation at year 1994. The contour interval is $5 \mu \mathrm{mol} / \mathrm{L}$.

[12] Surprisingly, GW1 and GW2 show very similar oceanic carbon uptake (Figure 2c). Over the 140 years of model integration, the GW1-GW2 difference in cumulative carbon uptake is $-3.4 \mathrm{PgC}$. This indicates that the marked reduction in the AMOC between GW1 and GW2 (Figure 2b) does not result in any significant change in the global ocean $\mathrm{CO}_{2}$ uptake. Locally, a small, but significant, decrease in $\mathrm{CO}_{2}$ uptake is simulated in the North Atlantic (Figure 3, between GW1 and GW2). This local difference explains the difference of $3.4 \mathrm{PgC}$ between these experiments. That said, this difference remains small. This may be due to the significant decreases in temperature and salinity in this region, that both increase $\mathrm{CO}_{2}$ solubility in $\mathrm{GW} 1$ relative to GW2, and both partly counteract the effect of circulation weakening only. We quantify this compensation using Exp 1-to-3.

[13] Sensitivity experiments show that the decrease in salinity ( -2.2 PSU in the North Atlantic in GW1, relative to GW2) tends to increase the cumulative uptake of $\mathrm{CO}_{2}$ by 16.0 PgC. The decrease in temperature $(-1.4 \mathrm{~K}$ in the North Atlantic in GW1, relative to GW2) increases cumulative $\mathrm{CO}_{2}$ uptake by $9.4 \mathrm{PgC}$. The increased sea-ice cover only has a small impact of $+1.1 \mathrm{PgC}$. Under linear approximation (supported by Joos et al. [1999] and Matear and Hirst [1999] studies), we estimate that the effect of "circulation + biology" when the AMOC weakening is large (GW1) drives a $29.9 \mathrm{PgC}$ decrease in $\mathrm{CO}_{2}$ cumulative uptake (as compared to GW2), thereby explaining the negative impact of land-ice melting and associated AMOC reduction on ocean $\mathrm{CO}_{2}$ uptake. Indirect effects counteract the direct dynamical effect by as much as $89 \%$, such that the total GIS melting and induced AMOC weakening have a small impact on oceanic carbon uptake over century time-scales, but could be larger on longer time-scales (millennial), according to the studies from Marchal et al. [1998] and Schmittner et al. [2007]. Figure 4 illustrates the quantification of the different compensating effects. Salinity changes play an important damping role on ocean $\mathrm{CO}_{2}$ uptake. The 2.2 PSU surface salinity decrease in the North Atlantic between GW1 and GW2 is due to both land-ice melting and AMOC weakening. A salinity budget north of $40^{\circ} \mathrm{N}$ in the North Atlantic shows that $30 \%$ of the changes are due to the direct freshening of GIS melting, the rest being due to AMOC changes affecting salinity transport. The large effect

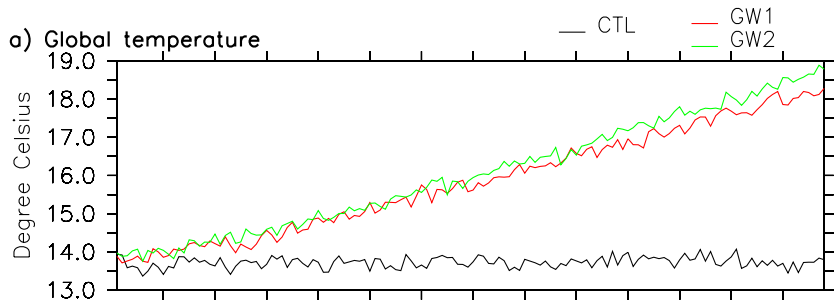

b) AMOC index

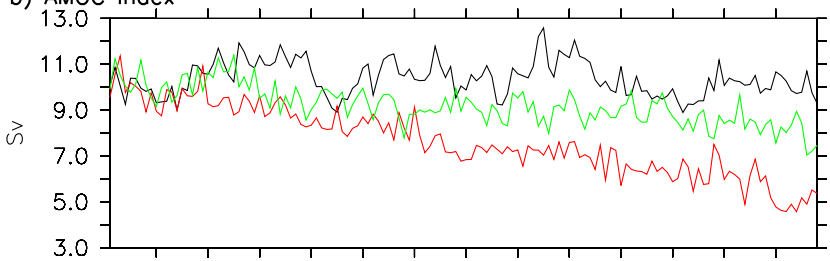

c) Ocean $\mathrm{CO} 2$ uptake

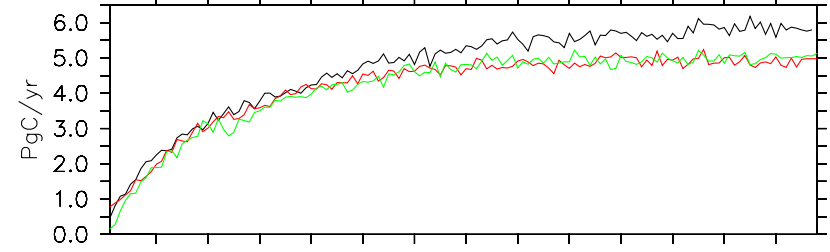

d) Integrated ocean $\mathrm{CO} 2$ uptake

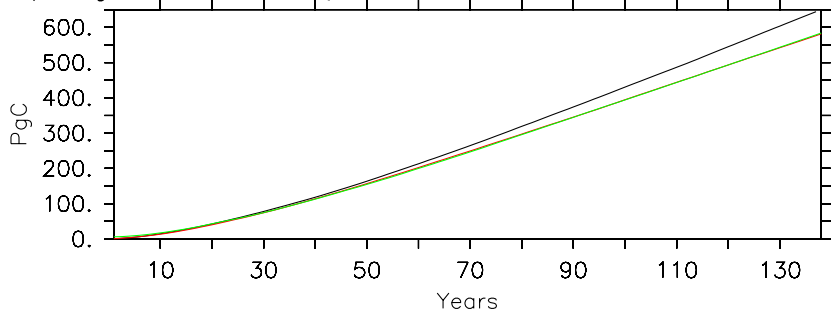

Figure 2. (a) Global mean evolution of atmospheric temperature at $2 \mathrm{~m}$. (b) AMOC index evolution, defined as the maximum of the Atlantic meridional overturning circulation between $500 \mathrm{~m}$ and $5000 \mathrm{~m}$ depth. (c) Projected annual ocean $\mathrm{CO}_{2}$ uptake as a function of time. (d) Same as in Figure 2c but for the cumulative ocean $\mathrm{CO}_{2}$ uptake. In black is CTL simulation, in red GW1, and in green GW2. A $1 \% / \mathrm{yr}$ increase of $\mathrm{CO}_{2}$ emissions starting from 1860 conditions is applied. 


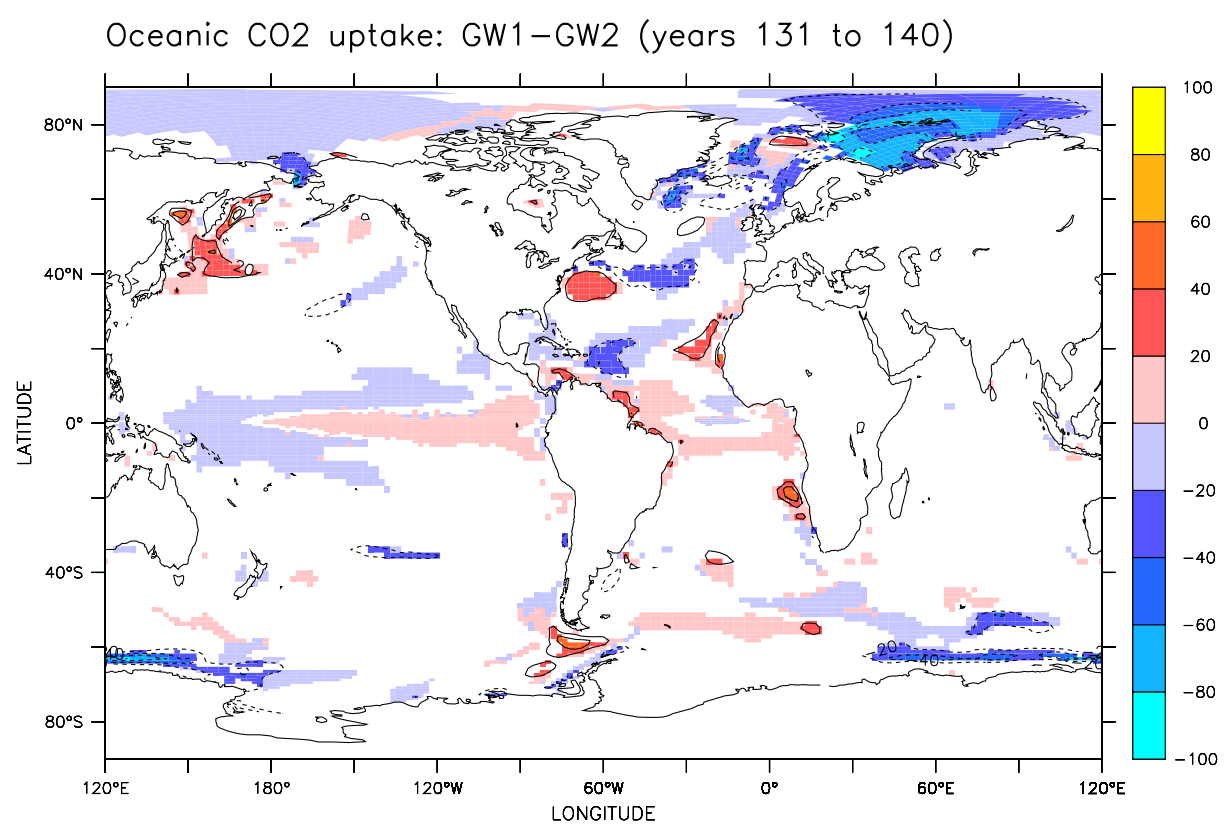

Figure 3. Difference between GW1 and GW2 in ocean $\mathrm{CO}_{2}$ uptake at $4 \times \mathrm{CO}_{2}$. The contour interval is $20 \mathrm{gC} \cdot \mathrm{m}^{-2} \cdot \mathrm{yr}^{-1}$. Colored zones correspond to the $99 \%$ student test significant differences.

of salinity on the $\mathrm{CO}_{2}$ uptake is due to change in carbonate chemistry coefficients with salinity. Alkalinity concentrations are very similar in Exp 2 to GW2 and therefore cannot explain the difference in $\mathrm{CO}_{2}$ uptake observed with GW2.

[14] As it impacts $\mathrm{CO}_{2}$ exchange with the atmosphere over longer timescales, it is also important to consider oceanic storage of anthropogenic carbon. The amount of carbon stored at depth is smaller in GW1 than in GW2 by up to $66 \mu \mathrm{mol} / \mathrm{L}$ at $60^{\circ} \mathrm{N}$ due to differences in water masses ventilation. We show here that induced changes in AMOC impact anthropogenic carbon distribution in the ocean's interior and that this would influence oceanic carbon transport to lower latitudes. This therefore has the potential to impact outgassing on millennial time scale.

\section{Discussions and Conclusions}

[15] We have examined the hypothetical effect of GIS melting and associated AMOC changes on the ocean $\mathrm{CO}_{2}$ uptake. To this end, we used a coupled climate model and an oceanic biogeochemical model to simulate the climate response to a $1 \% / \mathrm{yr}$ atmospheric $\mathrm{CO}_{2}$ increase (up to $4 \times$ $\mathrm{CO}_{2}$ ). Two parameterizations of GIS melting result in two different transient simulations that exhibit significant differences in the AMOC weakening. We show that the climate warming induced by the $\mathrm{CO}_{2}$ increase leads to a $11 \%(70.5 \mathrm{PgC})$ reduction in the ocean $\mathrm{CO}_{2}$ uptake. The GIS melting and associated weakening in the AMOC itself only result in a $3.4 \mathrm{PgC}$ decrease in cumulative ocean $\mathrm{CO}_{2}$ uptake after 140 years. This small impact is a result of compensating effects: (1) A decrease in salinity $(+16 \mathrm{PgC})$ and temperature $(+9.4 \mathrm{PgC})$, as well as an increase in seaice cover $(+1.1 \mathrm{PgC})$ due to land-ice melting and $\mathrm{AMOC}$ weakening tend to increase $\mathrm{CO}_{2}$ uptake. (2) Circulation and biological changes, determined by difference assuming linearity, result in a global decrease in $\mathrm{CO}_{2}$ uptake by as much as $29.9 \mathrm{PgC}$.
[16] These small differences in $\mathrm{CO}_{2}$ uptake due to GIS melting are however stored at depth. This storage is therefore effective for long time scales as the differences in surface $\mathrm{CO}_{2}$ uptake in the North Atlantic due to Greenland melting will accumulate over time. This would lead to potentially significant differences in atmospheric $\mathrm{CO}_{2}$ over longer timescales.

[17] Finally, we argue that the AMOC impact on $\mathrm{CO}_{2}$ uptake, here induced by GIS melting, cannot be captured by only integrating an oceanic carbon model with velocity

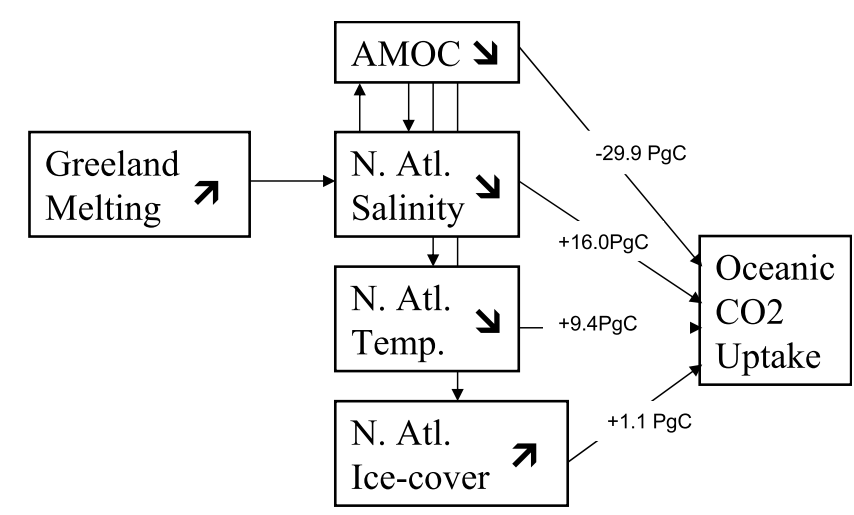

Figure 4. Scheme of the mechanisms at play in this study. The GIS melting implied a change in salinity in the North Atlantic (N. Atl.) that affects the AMOC and thus the temperature (Temp.) and sea-ice cover. We quantify the effect of temperature by the difference between Exp1 and GW2, the effect of salinity by Exp2-GW2, and sea-ice by Exp3-GW2. The direct circulation (velocity and biology) impact of the AMOC changes is evaluated under linear assumption by the difference between GW1-GW2 and the sum of Exp1-3 minus GW2. All these figures appear in the different arrows. 
fields from a pre-industrial simulation and thermodynamics from a scenario [Sarmiento and Le Quéré, 1996], because both fields influence each other. Salinity and temperature changes associated with circulation changes can actually counteract direct circulation changes effect on oceanic $\mathrm{CO}_{2}$ uptake.

[18] Acknowledgments. We thank Alessandro Tagliabue who kindly proofread the manuscript. This study benefited from interesting discussions with P. Friedlingstein, P. Cadule and A. Tagliabue. We gratefully acknowledge the constructive comments from two anonymous reviewers. The computing time was provided by the Commissariat a l'Energie Atomique (CEA). This work was supported by the Environment and Climate Programme of the European Community (CARBOOCEAN contract 511176).

\section{References}

Aumont, O., and L. Bopp (2006), Globalizing results from ocean in-situ iron fertilization studies, Global Biogeochem. Cycles, 20, GB2017, doi:10.1029/2005GB002591.

Cox, P., R. A. Betts, C. D. Jones, S. A. Spall, and I. J. Totterdell (2000), Acceleration of global warming due to carbon-cycle feedbacks in a coupled climate model, Nature, 408, 184-187.

Etheridge, D. M., et al. (1998), Historical $\mathrm{CO}_{2}$ records from the Law Dome DE08, DE08-2, and DSS ice cores, in Trends: A Compendium of Data on Global Change, Carbon Dioxide Inf. Anal. Cent., Oak Ridge Natl. Lab., U.S. Dep. of Energy, Oak Ridge, Tenn.

Friedlingstein, P., L. Bopp, P. Ciais, J. Dufresne, L. Fairhead, H. LeTreut, P. Monfray, and J. Orr, (2001) Positive feedback between future climate change and the carbon cycle, Geophys. Res. Lett., 28, 1543-1546.

Friedlingstein, P., et al. (2006), Climate-carbon cycle feedback analysis: Results from $\mathrm{C}^{4} \mathrm{MIP}$ model intercomparison, J. Clim., 19, 3337-3353.

Hansen, J., A. Lacis, D. Rind, G. Russell, P. Stone, I. Fung, R. Ruedy, and J. Lerner (1984), Climate sensitivity: Analysis of feedback mechanisms, in Climate Processes and Climate Sensitivity, Geophys. Monogr. Ser. vol. 29, Maurice Ewing Ser. vol. 5, edited by J. E. Hansen and T. Takahashi, pp. 130-163, AGU, Washington, D. C.

Joos, F., et al. (1999), Global warming and marine carbon cycle feedbacks an future atmospheric $\mathrm{CO}_{2}$, Science, 284, 464-467.

Keeling, C. D., and T. P. Whorf (2005), Atmospheric $\mathrm{CO}_{2}$ records from sites in the SIO air sampling network, in Trends: A Compendium of Data on Global Change, Carbon Dioxide Inf. Anal. Cent., Oak Ridge Natl. Lab., U.S. Dep. of Energy, Oak Ridge, Tenn.

Klepper, O., and B. J. de Haan (1995), A sensitivity study of the effect of global change on ocean carbon uptake, Tellus, Ser. B, 47, 490-500.

Marchal, O., T. F. Stocker, and F. Joos (1998), Impact of oceanic reorganizations on the ocean carbon cycle and atmospheric carbon dioxide content, Paleoceanography, 13, 225-244.

Marti, O., et al. (2005), The new IPSL climate system model: IPSL-CM4, Note Pôle Modelisation 26, 88 pp., Inst. Pierre Simon Laplace, Paris.

Matear, R. J., and A. C. Hirst (1999), Climate change feedback on the future oceanic $\mathrm{CO}_{2}$ uptake, Tellus, Ser. B, 51, 722-733.

Meehl, G. A., G. J. Boer, C. Covey, M. Latif, and R. J. Stouffer (2000), The Coupled Model Intercomparison Project (CMIP), Bull. Am. Meteorol. Soc., 81, 313-318.

Plattner, G. K., F. Joos, T. F. Stocker, and O. Marchal (2001), Feedback mechanisms and sensitivities of ocean carbon uptake under global warming, Tellus, Ser. B, 53, 564-592.

Sabine, C. L., et al. (2004), The oceanic sink for anthropogenic $\mathrm{CO}_{2}$, Science, 305, 367-371.

Sarmiento, J. L., and C. Le Quéré (1996), Oceanic carbon dioxide uptake in a model of century-scale global warming, Science, 274, 1346-1350.

Sarmiento, J. L., T. M. C. Hughes, R. J. Stouffer, and S. Manabe (1998), Simulated response of the ocean carbon cycle to anthropogenic climate warming, Nature, 393, 245-249.

Schmittner, A., E. Brook, and J. Ahn (2007), Impact of the ocean's overturning circulation on atmospheric $\mathrm{CO}_{2}$, in Ocean Circulation: Mechanisms and Impacts, Geophys. Monogr. Ser., vol. 173, edited by A. Schmittner, J. Chiang, and S. Hemming, pp. 209-246, AGU, Washington, D. C.

Swingedouw, D., P. Braconnot, and O. Marti (2006), Sensitivity of the Atlantic Meridional Overturning Circulation to the melting from northern glaciers in climate change experiments, Geophys. Res. Lett., 33, L07711, doi:10.1029/2006GL025765.

Swingedouw, D., P. Braconnot, P. Delecluse, E. Guilyardi, and O. Marti (2007), The impact of global freshwater forcing on the thermohaline circulation: Adjustment of North Atlantic convection sites in a CGCM, Clim. Dyn., 28, 291-305.

L. Bopp, P. Braconnot, A. Matras, and D. Swingedouw, Laboratoire des Sciences du Climat et de 1'Environnement, L'Institut Pierre-Simon Laplace, Orme des merisiers, F-91191 Gif-sur-Yvette, France. (didier.swingedouw@ cea.fr) 